\title{
PENERAPAN STRATEGI PEMBELAJARAN THINK-PAIR-SHARE DALAM PEMBELAJARAN MATEMATIKA MATERI BANGUN DATAR PERSEGI PANJANG
}

\author{
Musdiani $^{1}$ \\ ${ }^{1}$ Program Studi Pendidikan Guru Sekolah Dasar Universitas Bina Bangsa Getsempena \\ Email: musdiani@bbg.ac.id
}

\begin{abstract}
Abstrak: Tujuan penelitian ini adalah untuk meningkatkan hasil belajar Matematika materi Bangun Datar Persegi Panjang pada siswa kelas V dengan penerapan model pembelajaran kooperatif think-pairshare di SD Negeri 18 Punge Blang Cut Banda Aceh. Metode yang digunakan dalam penelitian ini adalah metode Penelitian Tindakan Kelas. Teknik pengumpulan data yang digunakan yaitu test dan observasi. Adapun yang menjadi populasi dalam penelitian ini adalah seluruh siswa kelas V SD Negeri 18 Punge Blang Cut Banda Aceh. Hasil yang di diperoleh dari penelitian ini yaitu kemampuan siswa kelas V SD Negeri 18 Punge Blang Cut Banda Aceh dalam memahami pembelajaran matematika materi bangun datar persegi panjang dengan menggunakan metode kooperatif think-pair-share mengalami peningkatan. Selama pembelajaran berlangsung adanya interaksi yang baik antara siswa dengan penulis sebagai obsever, sehingga terciptanya suasana belajar yang menyenangkan. Nilai yang diperoleh siswa dalam proses belajar pada saat pre test dan post test dalam siklus I mengalami perubahan yang signifikan. Pada siklus I nilai persentase siswa dalam pre test yaitu $45,62 \%$ sedangkan pada saat post test mendapatkan persentase $58,75 \%$.
\end{abstract}

Kata Kunci: Pembelajaran, model pembelajaran kooperatif think-pair-share, Matematika

\section{PENDAHULUAN}

Salah satu masalah yang dihadapi dunia pendidikan kita adalah masalah lemahnya proses pembelajaran, dimana anak kurang didorong untuk mengembangkan kemampuan berpikir. Proses pembelajaran dikelas diarahkan kepada kemampuan anak untuk memahami informasi. Kenyataan ini berlaku salah satunya pada mata pelajaran matematika. Karena strategi pembelajaran berpikir tidak digunakan secara baik dalam setiap proses pembelajaran di kelas. Untuk itu Peranan dunia pendidikan dalam mempersiapkan anak didik agar optimal dalam kehidupan bermasyarakat, maka proses dan model pembelajaran perlu terus diperbaharui.

Meningkatkan hasil belajar khususnya belajar matematika menjadi menyenangkan. Untuk mengatasi masalah tersebut di atas, sebagai alternatif pembelajaran inovatif yang dapat meningkatkan aktifitas siswa, meningkatkan penguasaan materi dan mutu pembelajaran matematika sehingga dapat meningkatkan hasil belajar siswa, maka pembelajaran kooperatif dapat diterapkan.

Pembelajaran kooperatif merupakan salah satu model pembelajaran yang berorientasi pada pendekatan konstruktivis artinya siswa aktif dalam memperoleh pengetahuan dan mereka membangun sendiri pengetahuan tersebut. Model pembelajaran kooperatif ini memanfaatkan kecenderungan siswa untuk berinteraksi dengan orang lain. Selain unggul dalam membantu siswa memahami konsep-konsep sulit, model ini sangat berguna untuk membantu siswa menumbuhkan kemampuan kerja sama, berfikir kritis, dan kemampuan membantu teman.

Cooper (1999) dan Heinich (2002) menjelaskan bahwa pembelajaran kooperatif sebagai metode pembelajaran yang melibatkan kelompok-kelompok kecil yang heterogen dan siswa bekerja sama untuk mencapai tujuan-tujuan dan tugas-tugas akademik bersama, sambil bekerja sama belajar keterampilan-keterampilan kolaboratif dan social. Anggota-anggota kelompok memiliki tanggung jawab dan saling bergantung 
antara satu sama lain untuk mencapai tujuan bersama. Berdasarkan beberapa definisi diatas dapat dikatakan bahwa belajar kooperatif mendasarkan pada suatu ide bahwa siswa bekerja sama dalam kelompok dan sekaligus masing-masing bertanggung jawab pada aktivitas belajar anggota kelompoknya, sehingga seluruh anggota kelompok dapat menguasai materi pelajaran dengan baik.

Pembelajaran kooperatif merupakan metodologi pengajaran yang dapat dijadikan dan efektif untuk mengajarkan dan membelajarkan matematika dan membantu menjadikan matematika menarik dan bisa di nikmati oleh siswa maupun guru, sehingga dapat meningkatkan hasil belajar siswa untuk belajar matematika. Strategi-strategi kooperatif bisa di integrasikan pada semua tingkatan sekolah dan untuk semua tema matematika. Siswa belajar bekerjasama dengan siswa lain dan berkomunikasi dalam bahasa matematika. Suasana kelas kooperatif cenderung santai dan informal, bantuan selalu ada, pertanyaan pertanyaan diajukan secara bebas dan dijawab, sehingga siswa pemalu bisa menjadi mudah untuk terlibat. Banyak siswa yang menunjukkan minat tinggi dalam aktivitas-aktivitas matematika dan memiliki kesempatan yang lebih menarik dan lebih kreatif.

Think-Pair-Share adalah suatu metode pembelajaran kooperatif yang memberi siswa waktu untuk berfikir dan merespon serta saling bantu satu sama lain (Tabany , 2017). Pembelajaran kooperatif Think-Pair-Share (TPS) yaitu melatih siswa untuk saling membantu antar anggota dalam memahami pelajaran ataupun dalam menyelesaikan tugas belajar. Siswa yang lemah akan mendapat bantuan dari temannya yang lebih pandai. Sebaliknya, siswa yang pandai dapat mengembangkan kemampuannya dengan materi pelajaran yang telah dikuasainya kepada temannya yang berkemampuan rendah, sehingga pembelajaran kooperatif memberi peluang kepada siswa yang berbeda latar belakang dan kondisi untuk bekerja saling bergantungan satu sama lain atas tugas-tugas bersama serta saling belajar untuk saling menghargai satu sama lain.

Menurut pengamatan awal penulis pada Sekolah Dasar Negeri 18 Punge Blang Cut Banda Aceh penulis melihat suatu masalah dalam mata pelajaran matematika materi bangun datar persegi panjang pada siswa kelas V. Hal ini terlihat dari nilai yang rendah pada tahun lalu hanya rata-rata 6,0. Masalah tersebut sangat berpengaruh terhadap hasil belajar yang dicapai oleh siswa dalam mata pelajaran matematika. Oleh karena itu, untuk lebih meningkatkan hasil belajar siswa tersebut, penulis mencoba mengoptimalkan penerapan strategi pembelajaran kooperatif model think-pair-share dalam pembelajaranya, dengan tujuan agar siswa lebih aktif dalam belajar serta menyukai mata pelajaran matematika. Dengan adanya model pembelajaran kooperatif think-pair-share hasil belajar siswa kelas V SD Negeri 18 Punge Blang Cut Banda Aceh dalam mata pelajaran matematika mengalami peningkatan.

\section{METODE PENELITIAN}

Penelitian ini adalah penelitian tindakan kelas. Pendekatan yang digunakan dalam penelitian ini yaitu pendekatan kuantitatif. Populasi penelitian adalah seluruh siswa kelas V SD Negeri 18 Punge Blang Cut Banda Aceh, dengan rincian jumlah keseluruhan siswa sebanyak 16 orang. pengumpulan data dilakukan dengan cara memberikan Tes dan Observasi. Test diberikan dengan maksud untuk mengetahui apakah adanya peningkatan hasil belajar siswa kelas V SD Negeri 18 Punge Blang Cut Banda Aceh sebelum dan sesudah diberikan perlakuan. Observasi dilakukan untuk 
menilai hasil dan proses belajar, tingkah laku siswa pada saat belajar, kegiatan diskusi siswa dan kebersamaan siswa saat belajar.

\section{HASIL PENELITIAN DAN PEMBAHASAN}

\section{Hasil Penelitian}

Penelitian ini dilakukan pada siswa kelas V SD Negeri 18 Punge Blang Cut Banda Aceh yang beralamat di Jl. Punge Blang Cut, Kec. Ingin Jaya, Banda Aceh. Dengan judul penelitian "Penerapan Pembelajaran Kooperatif Model Think-Pair-Share dalam Meningkatkan Hasil Belajar Matematika Materi Bangun Datar Persegi Panjang pada Siswa Kelas V SD Punge Blang Cut Banda Aceh”. Sebelum melaksanakan penelitian, penulis telah melakukan observasi ke sekolah untuk melihat situasi dan kondisi sekolah serta berkonsultasi dengan guru tentang siswa yang akan diteliti. Kemudian penulis mempersiapkan instrument pengumpulan data yang terdiri dari lembaran observasi aktivitas siswa, lembaran pretest dan post test siswa, serta rencana pelaksanaan pembelajaran I, II.

Penelitian ini dilakukan dalam dua siklus, tindakan siklus pertama dilakukan pada minggu keempat juni 2012 dan tindakan siklus kedua dilakukan pada minggu pertama bulan juli 2012. Penulis sebagai guru peneliti dan dibantu oleh guru kelas V bertindak sebagai observer dan berfungsi sebagai teman diskusi pada tahap refleksi. Adapun hasilnya termuat pada tabel dibawah ini:

Tabel 1 Hasil Setiap Aspek PTK pada Siklus I

\begin{tabular}{|l|l|c|l|}
\hline No & \multicolumn{1}{|c|}{$\begin{array}{c}\text { Aspek } \\
\text { Penelitian }\end{array}$} & $\begin{array}{c}\text { Tindakan Siklus } \\
\text { I }\end{array}$ & \multicolumn{1}{|c|}{ Refleksi } \\
\hline 1. & Aktifitas siswa & $75 \%$ & $\begin{array}{l}\text { Siswa masih perlu penjelasan dari } \\
\text { guru, bagaimana bentuk-bentuk } \\
\text { dari bangun datar persegi panjang }\end{array}$ \\
\hline 2. & $\begin{array}{l}\text { Ketuntasan } \\
\text { belajar klasikal }\end{array}$ & $58,75 \%$ & $\begin{array}{l}\text { Perlu adanya pemahaman dari } \\
\text { guru terhadap kebersamaan siswa } \\
\text { dalam belajar. }\end{array}$ \\
\hline
\end{tabular}

Dalam pengolahan data hasil observasi pembelajaran matematika siswa pada materi bangun datar persegi panjang dengan menggunakan metode kooperatif thinkpair-share. Penulis menggunakan cara yang dikembangkan oleh Nana Sudjana dalam Buku Penilaian Hasil Proses Belajar Mengajar (2004:132-133) sebagai berikut: Aktivitas Siswa $=$ Skor Hasil Observasi $\mathrm{x} 100 \%$

( Jumlah aspek yang diamati x Skor maksimum untuk setiap aspek )

Dimana :

12 : Contoh skor hasil observasi

4 : Jumlah skor yang diamati

$4 \quad$ : Skor maksimum untuk setiap aspek

$100 \%$ : Bilangan konstanta 
Tabel 2 Hasil Observasi Pembelajaran Matematika Siswa Siklus I

\begin{tabular}{|r|l|c|c|c|c|}
\hline \multicolumn{1}{|c|}{ No } & \multicolumn{1}{|c|}{ Aspek yang diamati } & \multicolumn{3}{|c|}{$\begin{array}{c}\text { Nilai } \\
\text { Pengamatan }\end{array}$} \\
\hline & & 4 & 3 & 2 & 1 \\
\hline 1. & $\begin{array}{l}\text { Perhatian siswa ketika proses } \\
\text { pembelajaran berlangsung }\end{array}$ & & $\sqrt{ }$ & & \\
\hline 2. & $\begin{array}{l}\text { Keseriusan siswa dalam } \\
\text { belajar matematika }\end{array}$ & $\sqrt{ }$ & & & \\
\hline 3. & $\begin{array}{l}\text { Minat belajar matematika } \\
\text { siswa }\end{array}$ & & $\sqrt{ }$ & & \\
\hline 4. & kebersamaan belajar siswa & & & $\sqrt{ }$ & \\
\hline
\end{tabular}

Keterangan:

4: Baik sekali

3: Baik

2: Cukup

1: kurang

Dari tabel di atas skor hasil observasi pembelajaran matematika siswa pada materi bangun datar persegi panjang dengan menggunakan metode kooperatif thinkpair-share siklus I adalah: $3+4+3+2=12$

Aktivitas Siswa $=$ Skor Hasil Observasi

Aktivitas siswa $=\frac{12}{4 \times 4} \times 100 \%$

Aktivitas Siswa $=\frac{12}{16} \times 100 \%$

Aktivitas Siswa $=75 \%$

\section{Pembahasan Siklus I}

a. Aktivitas Siswa Siklus I

Berdasarkan hasil observasi yang telah penulis lakukan dalam tindakan siklus I dalam kegiatan pelaksanaan tindakan kelas. Hasil aktivitas siswa dalam mengikuti pembelajaran matematika materi bangun datar persegi panjang dengan menggunakan metode kooperatif think-pair-share pada tindakan siklus I yaitu $75 \%$. Hal ini dilihat dari keseriusan siswa dalam mengikuti pembelajaran matematika materi bangun datar persegi panjang pada kategori baik sekali. Pada tindakan siklus I ini adanya peningkatan aktivitas siswa dalam mengikuti pelajaran matematika. Hal ini dibuktikan dari hasil observasi penulis yang tergolong dalam kategori, baik pada aspek perhatian siswa pada saat pembelajaran berlangsung dan pada minat belajar matematika siswa. Sedangkan pada aspek kebersamaan siswa tergolong dalam kategori cukup, artinya siswa masih perlu dilatih untuk saling berbagi antar sesama teman.

\section{b. Ketuntasan Belajar Klasikal Siswa Siklus I}

Hasil pembelajaran matematika siswa pada materi bangun datar persegi panjang dengan menggunakan metode kooperatif think-pair-share secara umum mengalami hasil prestasi yang cukup baik. Jika pada pre-test (tes awal) nilai persentase yang 
diperoleh hanya 45,62\% dan mengalami peningkatan nilai pada post-test (tes akhir) siklus I dengan persentase $58,75 \%$, dengan sajian data sebagai berikut:

Tabel 3 Nilai Hasil Pembelajaran Matematika siswa Siklus I

\begin{tabular}{|l|l|c|c|}
\hline No & \multicolumn{1}{|c|}{ Nama Siswa } & Pre-Test & Post-Test \\
\hline 1. & Ad & 40 & 60 \\
\hline 2. & AK & 40 & 60 \\
\hline 3. & CZ & 50 & 60 \\
\hline 4. & En & 40 & 50 \\
\hline 5. & KN & 50 & 55 \\
\hline 6. & MA & 40 & 55 \\
\hline 7. & M. A & 40 & 60 \\
\hline 8. & M. R & 60 & 65 \\
\hline 9. & Na & 60 & 65 \\
\hline 10. & NF & 60 & 65 \\
\hline 11. & NS & 40 & 50 \\
\hline 12. & T. R & 50 & 60 \\
\hline 13. & WA & 40 & 55 \\
\hline 14. & WY & 30 & 50 \\
\hline 15. & QS & 40 & 60 \\
\hline 16. & ZR & 50 & 70 \\
& & 730 & 940 \\
\hline
\end{tabular}

\subsection{Analisis Data}

Pengolahan data nilai hasil belajar matematika siswa pada materi bangun datar persegi panjang dengan metode kooperatif think-pair-share akan dianalisis dengan menggunakan metode deskriptif persentase yang dikembangkan oleh Nana Sudjana sebagai berikut:

$$
P=\frac{F \times 100 \%}{N}
$$

Dimana:

$$
\begin{array}{lc}
\mathrm{P} & \text { : Persentase } \\
\mathrm{F} & \text { : Frekuensi } \\
\mathrm{N} & \text { : Jumlah Sampel } \\
& \text { 100: } \text { Bilangan Konstanta }
\end{array}
$$

\section{c. Persentase Nilai Pembelajaran Matematika Siswa Siklus I}

Persentase nilai pembelajaran matematika siswa kelas V SD Negeri 18 Punge Blang Cut Banda Aceh pada siklus I akan dianalisis sesuai dengan rumus deskriptif persentase yang telah dijelaskan sebelumnya. Adapun bentuk rumus tersebut adalah sebagai berikut:

$P=\frac{F \times 100 \%}{N}$ 
Dengan menggunakan rumus di atas, persentase nilai pembelajaran matematika siswa pada materi bangun datar persegi panjang dengan menggunakan metode kooperatif think-pair-share pada pre test siklus I adalah sebagai berikut:

$$
P=\frac{F x 100 \%}{N}
$$

Dimana Nilai:

$F=730$

$\mathrm{N}=(16 \times 100)$

Jadi,

$\mathrm{P}=\frac{730}{(15 \times 100)} \times 100 \%$

$\mathrm{P}=\frac{730}{1600} \times 100 \%$

$\mathrm{P}=45,62 \%$

Persentase nilai pembelajaran matematika siswa pada materi bangun datar persegi panjang pada siswa kelas V SD Negeri 18 Punge Blang Cut Banda Aceh pada pre-test siklus I adalah $45,62 \%$.

Persentase nilai pembelajaran matematika siswa pada materi bangun datar persegi pangjang di post-test siklus I adalah sebagai berikut:

$P=\frac{F \times 100 \%}{N}$

Dimana Nilai:

$F=940$

$\mathrm{N}=(16 \times 100)$

Jadi,

$\mathrm{P}=\frac{940}{(16 \times 100)} \times 100 \%$

$\mathrm{P}=\frac{940}{1600} \times 100 \%$

$\mathrm{P}=58,75 \%$

Jadi persentase nilai pembelajaran matematika siswa pada materi bangun datar persegi panjang dengan menggunakan metode think-pair-share siswa kelas V SD Negeri 18 Punge Blang Cut banda Aceh pada post-test siklus I adalah 58,75\%, sedangkan pada pre-test siklus I nilai persentasenya yaitu 45,62\%. Dengan demikian, adanya peningkatan persentase nilai pembelajaran matematika pada materi bangun datar persegi panjang dengan menggunakan metode kooperatif think-pair-share dari pre-test ke post-test siklus I sebanyak $13,13 \%$. 


\section{KESIMPULAN}

Nilai yang diperoleh siswa dalam proses belajar matematika siswa dari pre test ke post test pada siklus I mengalami peningkatan yaitu nilai pre test sebanyak 730 dan nilai post test sebanyak 940, sehingga dapat dipersentasekan yaitu nilai pre test siklus I 45,62 \%, sedangkan nilai post test siklus I yaitu 58,75\%. Dengan demikian, maka terjadi peningkatan antara nilai pre test ke nilai post test sebanyak 13,13\%. Nilai aktifitas siswa selama pembelajaran berlangsung yaitu $75 \%$ dan ketuntasan belajar klasikalnya yaitu $58,75 \%$.

\section{DAFTAR PUSTAKA}

Al-Tabany, T. I. B. (2017). Mendesain Model Pembelajaran Inovatif, Progresif, Dan Konteksual. Prenada Media.

Cooper, J.L. Robinson, P.\& Miyazoki, Y. 1999.Promoting core skills through cooperative Learning. Dunne, A. The learning society. London: Kogan Page Limited.

Davidson, N. \& Kroll, D.1., 1991, An Overview of Research on Cooperative LearningRelated to Mathematics. Journal for Research in Mathematics Education.

Heruman, Model Pembelajaran Matematika di Sekolah Dasar (Bandung : Rosda Karya, 2007).

Heinich, R. Molenda, M. Russell, J.D \& Smaldino, S.E. 2001. Instructional media and technology for learning. New Jersey : Prantice Hall, Inc.

Jonson, D,W. \& Johson, R.1991, Learning Together and Alone., Cooperative, and Individualistic Learning,. Boston: Allyn and Bacon.

Lexy J. Moleong, 2005. Metodologi Penelitian Kualitatif (Bandung : Remaja Rosdakarya, ),

Mulyasa, E. 2009. Praktek Penelitian Tindakan Kelas. PT. Remaja Rosda Karya: Bandung.

Nana, Sudjana. 2004. Penilaian Hasil Proses Belajar Mengajar. PT. Remaja Rosda Karya, Bandung.

Slavin. R.E. 1995, Cooperative Learning: Theory, Research, and Practtice. Boston Allyn and Bacon.

Sa'dijah, Cholis. 2006. Penerapan Pembelajaran Kooperatif Think Pair Share TPS ( Malang: Lembaga Penelitian UM )

Sholmon, Sharan, 2009. Handbook of Coopertive Learning. (Yogyakarta: Imperium,).

Z. A., M., \& M. Nur Hakim. (2018). The implementation of cooperative learning think pair share strategy in teaching reading comprehension at junior high school. Ijlecr - international journal of language education and culture review, 4(2), 155-161. https://doi.org/10.21009/IJLECR.052.19 